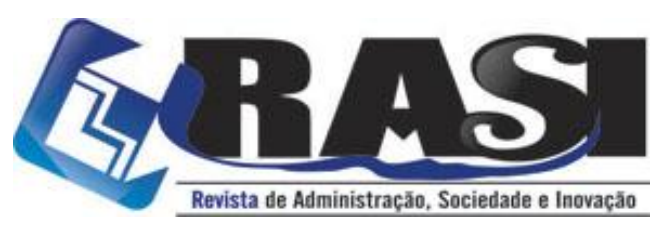

http://www.rasi.uff.br

RASI, Volta Redonda/RJ, v. 3, n. 1, pp. 48-65, jan./jun. 2017

\title{
Adoção de Tecnologia na Organização: o caso de uma empresa brasileira do segmento de automação industrial
}

\author{
Natan de Souza Marques (USP) - natanmarques@usp.br \\ Aline Mariane de Faria (USP) - alinefaria@usp.br \\ Roberto Sbragia (USP) - rsbragia@usp.br \\ Bassiro Só (USP) - bassiro@usp.br
}

\section{RESUMO:}

Com a abertura dos processos de inovação nas empresas, a adoção de tecnologia passou a ser fundamental. No presente artigo, analisa-se como uma organização do segmento de automação industrial toma decisões de adoção de tecnologia. Assim, busca-se identificar quais fatores foram considerados na tomada de decisão. Para tanto, o estudo de caso foi utilizado como método de pesquisa, tendo como técnica de coleta de dados a entrevista estruturada com o gerente de Pesquisa, Desenvolvimento e Inovação da organização estudada. Como resultados, pôde-se verificar que o processo de adoção de tecnologia é realizado de forma conjunta, por um comitê técnico e de qualidade; que os esforços comerciais dos fornecedores não foram considerados no momento da adoção; que a decisão de adoção foi impulsionada principalmente pela consideração das características percebidas da inovação; o ambiente externo, mediante pressões competitivas a jusante na cadeia de valor, influenciou bastante a decisão de adoção; e também, que as características dos adotadores foram consideradas pela organização.

PALAVRAS-CHAVE: adoção de tecnologia; protocolo HART; automação industrial.

\section{Technology adoption on Organization: the case of a Brazilian company of industrial automation.}

\begin{abstract}
:
With the opening of innovation processes in companies, the adoption of technology has become fundamental. In this article, we analyze how an organization of the industrial automation segment makes technology adoption decisions. Thus, we sought to identify which factors were considered in decision making. For that, the case study was used as a research method, having as data collection technique the structured interview with the research, development and innovation manager of the organization studied. As a result, it can be verified that the process of adoption of technology is carried out jointly by a technical and quality committee; That the commercial efforts of suppliers were not considered at the time of adoption; That the adoption decision was driven mainly by the consideration of the perceived characteristics of innovation; The external environment, through competitive pressures downstream in the value chain, greatly influenced the decision to adopt; And also that the characteristics of the adopters were considered by the organization.
\end{abstract}

KEY-WORDS: Technology adoption; HART protocol; Industrial automation.

\section{S Universidade Fluminense}

R. Desembargador Ellis Hermydio Figueira, 783, Bloco A, sl. 304, Aterrado. 27213-145 - Volta Redonda, RJ - Brasil www.uff.br

Copyright (C) 2017 RASI. Todos os direitos, até mesmo de tradução, são reservados. É permitido citar parte de artigos sem autorização prévia, desde que seja identificada a fonte. 


\section{Adoção de Tecnologia na Organização: o caso de uma empresa brasileira do segmento de automação industrial}

\section{Introdução}

As organizações empresariais, nos últimos anos, vêm buscando fortemente direcionar seus negócios para alcançar vantagem competitiva por meio da inovação, inserindo-se na onda da inovatividade (Kumpe e Bolwijn, 1994). Essa postura tem colocado as organizações diante de estratégias de inovação, sendo elas direcionadas para o enriquecimento de portfólio, liderança competitiva e instigação do consumidor (Bowonder et al, 2010). Essas estratégias fazem com que as organizações tenham que decidir entre desenvolver internamente ou adquirir de fora.

Abordagens como a inovação aberta (Chesbrough, 2003) são cada vez mais consideradas nas organizações, as quais estão a todo o momento analisando possibilidades de aquisição de competências por meio da abertura de seus processos de pesquisa e desenvolvimento, mediante a utilização de estratégias orientadas para esse fim. Uma vez que a organização escolha adquirir tecnologias externas, torna-se importante entender o porquê da adoção, assim como os fatores que são determinantes para que uma organização tome a decisão de adotar determinada tecnologia. A complexidade dessa tarefa reside no fato de que os atributos considerados na adoção de determinada inovação dependem da organização que a adota e das características da própria inovação (Rogers, 2003). Nesse sentido, o presente artigo busca entender como uma empresa do segmento de automação industrial adota tecnologias. Para atender esse objetivo, buscou-se, operacionalmente, identificar os fatores que foram considerados na adoção da tecnologia analisada.

As próximas seções estão estruturadas da seguinte forma: na seção 02 é apresentada a revisão bibliográfica que dá suporte à pesquisa; na seção 03 descreve-se a metodologia utilizada para a condução da pesquisa, abordando a estratégia de pesquisa, os modelos utilizados, descrição da empresa e apresentação do caso estudado; na seção 04, apresenta-se a análise e discussão dos resultados; e, por fim, na seção 05, faz-se a conclusão do trabalho e apresentam-se algumas considerações finais.

\section{Revisão Bibliográfica}

Ao longo da história, as organizações empresariais têm sido guiadas pelas exigências do mercado, o que têm fortemente direcionado a competição internacional, passando da busca por eficiência, no princípio, para a busca por inovatividade, nos tempos atuais (Kumpe e Bolwijn, 1994). Agora, a inovação, associada à eficiência e flexibilidade, assume um papel chave na busca por vantagens competitivas por parte das organizações. "A habilidade para inovar tem consequências diretas na habilidade de competir em níveis individuais, da firma, regional e nacional" (Neely \& Hii, 1998).

Muitas estratégias de inovação são utilizadas com vistas a criar essa vantagem competitiva, sendo elas direcionadas a três vertentes: enriquecimento de portfólio, liderança competitiva e instigação do consumidor (Bowonder et al, 2010). Essas três vertentes se desdobram em uma série de estratégias que podem ser utilizadas para tornar as empresas mais 
inovativas. Muitas delas colocam a organização diante da decisão de desenvolver as tecnologias internamente ou adquirir tecnologias externas, por meio da adoção de tecnologias.

\subsection{A Adoção de Tecnologias}

A adoção de tecnologia é abordada na literatura do ponto de vista da adoção por parte dos usuários (Rogers, 2003) e por parte das organizações (Rogers, 2003, Frambach \& Schillewaert, 2002; Nemoto, Vasconcellos \& Nelson, 2010; Thong \& Yap, 1995; Lunardi, Dolci \& Maçada, 2009; Naranjo-Gil, 2009; dentre outros). Rogers (2003) aborda a adoção de tecnologias analisando as variáveis determinantes da taxa de adoção, entendendo por taxa de adoção "a velocidade relativa com a qual uma inovação é adotada pelos membros de um sistema social" (Rogers, 2003). Assim, a mensuração dessa taxa refere-se ao número de indivíduos que adotam a tecnologia em um determinado período de tempo, e ela depende de algumas variáveis, tais como: atributos percebidos da inovação; tipos de decisão de inovação; canais de comunicação; natureza do sistema social; e medida dos esforços de promoção dos agentes de mudança.

Quando se refere aos atributos da inovação, Rogers (2003) aponta cinco: vantagem relativa; compatibilidade; complexidade; possibilidade de teste; e visibilidade. Em termos conceituais, a vantagem relativa da tecnologia se refere ao grau em que a inovação é percebida como sendo melhor do que aquela que a antecede, sendo expressa, frequentemente, como lucratividade econômica, prestigio social transmitido, dentre outros. A vantagem relativa é percebida de diferentes formas a depender das características do adotador e, principalmente, da própria tecnologia.

A compatibilidade, segundo Rogers (2003), é entendida como sendo o grau para o qual uma inovação é percebida como consistente com os valores existentes, experiências passadas, e necessidades dos potenciais adotadores. A compatibilidade de uma tecnologia pode se referir a três aspectos principais: (1) valores e crenças socioculturais; (2) ideias previamente introduzidas; e (3) necessidades dos clientes para a inovação. Quanto mais compatível a tecnologia estiver com os valores, experiências e necessidades, mais facilmente será absorvida e assumida como familiar a um indivíduo, no plano individual, ou a uma organização, no plano organizacional.

Por complexidade entende-se o grau para o qual uma inovação é percebida como relativamente difícil de ser entendida e utilizada. Quanto mais clara for a inovação para o usuário, mais fácil e maior será a taxa de adoção. Assim, segundo Rogers (2003), a complexidade apresenta uma relação inversa com a taxa de adoção, sendo que, quanto maior a complexidade da inovação menor será a taxa de adoção e vice-versa.

Outro atributo da inovação apontado por Rogers (2003) é a possibilidade de testagem da tecnologia. Segundo ele, esse atributo refere-se ao grau para o qual uma inovação pode ser experimentada em uma base limitada. Esse acesso à inovação por meio de possibilidade de teste da tecnologia apresenta uma relação positiva com a taxa de adoção. Ou seja, quanto mais fácil for a possibilidade de testagem da tecnologia, maior será a taxa de adoção de tecnologias relacionadas.

Por fim, o ultimo dos atributos apresentados por Rogers (2003) é a visibilidade da tecnologia a ser adotada, sendo entendida como o grau para o qual os resultados de uma inovação são visíveis para outros. Dessa forma, quanto mais fácil uma inovação for vista por outros, maior será a taxa de adoção. Como exemplo prático, o autor menciona a diferença entre tecnologias software e tecnologias hardware, sendo a primeira de mais difícil 
visualização, tendendo, portanto, a uma menor taxa de adoção, enquanto a segunda é de mais fácil visualização, o que a concede uma maior taxa de adoção.

Rogers (2003) chama a atenção para a mensuração desses atributos quando a unidade de análise são as organizações, e assim, se apoia em evidências empíricas de que os atributos podem ser percebidos de maneira diferente de uma organização para outra, podendo, por exemplo, existir outros atributos que influenciam na taxa de adoção, mas que, não foram contemplados anteriormente.

Tendo em vista as organizações como unidades de adoção de tecnologias, alguns estudos buscam abordar essa perspectiva, apresentando um framework conceitual da adoção de inovação em organizações, a exemplo de Frambach e Schillewaert (2002), modelo conceitual este utilizado como subsídio para a construção do roteiro de entrevista utilizado na pesquisa de campo que fundamentou esse artigo.

\subsection{O modelo de adoção de tecnologia de Frambach e Schillewaert (2002)}

Frambach e Schillewaert (2002) apresenta um framework conceitual de adoção de inovações nas organizações que contempla a adoção de inovações como um processo que caminha desde a conscientização em torno da inovação, passando pela consideração, intenção, decisão de adoção e uso continuado. Esse processo é influenciado por alguns outros aspectos, sendo ele: características percebidas da inovação, características dos adotadores e influências ambientais, sendo que, as características percebidas da inovação são, também, influenciadas por fatores como esforços comerciais do fornecedor, redes sociais e influências ambientais.

Para facilitar a visualização, a figura seguinte apresenta o modelo proposto pelos autores:

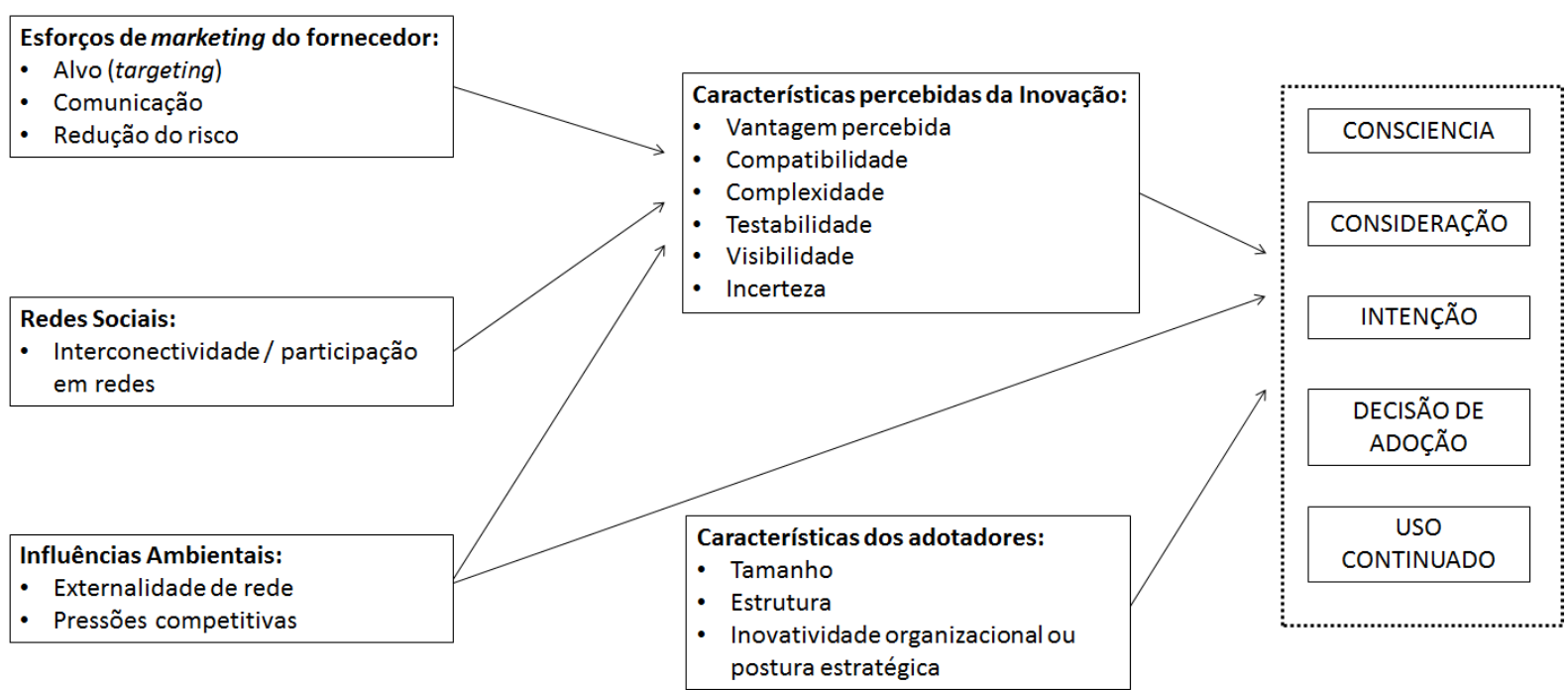

Figura 01 - Framework Conceitual de adoção de inovações em organizações proposto por Frambach e Schillewaert

FONTE: Frambach e Schillewaert (2002, p. 165).

O modelo proposto por Frambach e Schillewaert (2002), identificado na figura 1, sintetiza a visão dos fatores que influenciam o processo de adoção de tecnologias nas organizações. Os autores, fundamentados nos atributos da inovação proposto por Rogers 
(2003) e citados anteriormente nesse artigo, apontam as características percebidas da inovação como diretamente relacionada ao processo de adoção de tecnologia em organizações. Por Características percebidas, Frambach e Schillewaert (2002) citam a vantagem relativa da tecnologia, a compatibilidade da tecnologia, a complexidade, a possibilidade de testagem da tecnologia, a visibilidade, e a incerteza apresentada pela tecnologia. Os conceitos referentes às características percebidas de uma inovação foram tratados anteriormente, uma vez que Frambach e Schillewaert (2002) apoiam-se nos conceitos de atributos da inovação apontados por Rogers (2003).

Outro fator que se relaciona diretamente com a adoção de tecnologia em organizações é a característica dos adotadores. Frambach e Schillewaert (2002) mencionam como característica dos adotadores o tamanho, a estrutura, e a inovatividade organizacional ou postura estratégica. Esses fatores podem influenciar a decisão de adoção de uma tecnologia na organização e podem, também, contribuir para a percepção das características de uma inovação, uma vez que, os atributos percebidos podem variar em conformidade com as características da inovação, assim como, variam também de acordo com as próprias características da inovação em análise (Rogers, 2003).

Dos fatores que impactam diretamente no processo de adoção da tecnologia, têm-se também as influências ambientais. Essas influências ambientais relacionam-se diretamente com o processo de adoção das tecnologias e, também, com as características percebidas da inovação. Segundo Frambach e Schillewaert (2002), as influências ambientais materializamse nas externalidades de rede e nas pressões competitivas. A externalidade de rede acontece quando as organizações adotam tecnologias com base em um número de organizações no ambiente de mercado que adotaram a mesma tecnologia, e as pressões competitivas referemse à dinâmica e estrutura econômica do mercado. Em mercados com maior competitividade, a adoção de tecnologias pode ser condição sine qua non para a sobrevivência da organização, de tal forma que, quanto maior o nível de competição maior será o estímulo para a adoção de inovação nas organizações.

Além dos fatores mencionados até aqui, existem ainda aqueles que estão relacionados diretamente com as características percebidas da inovação. Esses fatores são as redes sociais e os esforços comerciais dos fornecedores. Por redes sociais Frambach e Schillewaert (2002) consideram a interconectividade ou participação em redes. Em termos gerais, refere-se à interação da organização com o ambiente em que atua. Essa interação interfere nas características percebidas de uma inovação à medida que permite à organização conhecer e se comunicar com outras organizações que já tenham adotado a tecnologia.

Com relação aos esforços comerciais dos fornecedores, Frambach e Schillewaert (2002) apontam três aspectos: alvo (targeting); comunicação; e redução do risco. Com relação ao alvo, os autores apontam que quanto mais focado e direcionado a tecnologia for, no sentido de ter sido desenvolvida objetivando potenciais adotadores de forma selecionada, maior será a possibilidade desses potenciais adotadores enxergarem na tecnologia atributos que o motivem a adquiri-la. A comunicação por parte do fornecedor da tecnologia, por sua vez, leva ao conhecimento do potencial adotador os atributos e a própria tecnologia em si, sendo que essa comunicação não apenas cria consciência, como também influencia a percepção dos potenciais adotadores com relação à tecnologia.

Por último, a redução do risco também é fator importante para a percepção das características da inovação por parte dos potenciais adotadores da tecnologia. Por redução do risco Frambach e Schillewaert (2002) consideram "a redução do risco associado aos primeiros 
adotadores de uma inovação, incluindo risco de implementação (uso), riscos financeiros e riscos operacionais" (Frambach \& Schillewaert, 2002, p. 166). A redução desses riscos apontados pelos autores contribui para que a adoção de uma inovação seja estimulada.

\subsection{Outros modelos de adoção de tecnologias identificados na literatura}

Thong e Yap (1995), buscando compreender a adoção de tecnologias em pequenos negócios, testou a relação de algumas variáveis na adoção de tecnologias de informação em pequenos negócios. Eles consideraram as características do CEO e as características organizacionais como variáveis independentes a serem testadas, tendo como variável dependente a adoção de tecnologias de informação.

Thong e Yap (1995) descobriram que, além do tamanho da organização, as características do CEO têm relação forte com a adoção de tecnologias de Informação em pequenos negócios. Basicamente, a inovatividade do CEO, a atitude do CEO para a adoção de tecnologias de informação, e o conhecimento que o CEO possui sobre tecnologia da informação são aspectos determinantes da adoção de tecnologias de informação em pequenas organizações.

Além do estudo de Thong e Yap (1995), outro estudo também apresenta contribuições no sentido de apresentar um modelo de adoção de tecnologia e aplicá-lo em uma organização de logística industrial, sendo ele: Nemoto, Vasconcellos e Nelson (2010). O modelo apresentado pelos autores foi construído com base no modelo de Frambach e Schillewaert (2002) e Rogers (2003), considerando assim, alguns fatores não considerados pelos modelos anteriormente apresentados.

No modelo apresentado por Nemoto, Vasconcellos e Nelson (2010) foram considerados os fatores "atributos da inovação"; "ambiente externo"; "fornecedores"; e "características organizacionais" como aspectos que afetam diretamente a decisão de adoção de inovações em organizações. Esse modelo se diferencia do modelo proposto por Frambach e Schillewaert (2002) na medida em que desconsidera possibilidades de influencias indiretas na decisão de adoção de inovação.

Esse modelo apresentado por Nemoto, Vasconcellos e Nelson (2010) fundamenta-se no modelo proposto por Frambach e Schillewaert (2002), porém, traz consigo algumas modificações interessantes de serem notadas. A principal delas é a ordem de influencia na decisão de adoção de tecnologia, ou seja, Frambach e Schillewaert (2002) consideram que os fornecedores aparecem relacionando diretamente com os atributos da inovação e os atributos da inovação relacionando diretamente com a decisão de adoção da inovação, enquanto que, Nemoto, Vasconcellos e Nelson (2010) consideram que os fornecedores não estão relacionados aos atributos, sendo todos eles relacionados diretamente com a decisão de adoção da inovação.

No mesmo sentido, o ambiente externo é considerado por Frambach e Schillewaert (2002) como relacionado diretamente aos atributos da inovação e também à decisão de adoção da tecnologia. Já para Nemoto, Vasconcellos e Nelson (2010), o ambiente externo influencia apenas a decisão de adoção da tecnologia, não influenciando diretamente os atributos da inovação. Além dessas mudanças, Nemoto, Vasconcellos e Nelson (2010) adicionam algumas variáveis não contempladas no modelo de Frambach e Schillewaert (2002), sendo elas a reputação e a dependência na parte dos fornecedores; as características da cadeia de produção, incerteza com relação ao mercado, e regulação do governo na parte do ambiente externo. 
Apesar das contribuições de Nemoto, Vasconcellos e Nelson (2010), adotaremos, neste trabalho, o modelo de Frambach e Schillewaert (2002) por entendermos que exista, nele, maior adequação ao formato de adoção de tecnologia por organizações, uma vez que ele aponta que o processo de adoção de tecnologia é influenciado diretamente por três aspectos (características percebidas da inovação; influências do ambiente; e características dos adotadores), sendo que, as características percebidas da inovação são influenciadas pelos esforços de marketing do fornecedor, redes sociais (social networks) e influências do ambiente.

Partimos do pressuposto de que os esforços de marketing do fornecedor e a participação em redes contribuem para que as organizações percebam as características da adoção, porém, não são suficientes para fazê-las adotar a tecnologia, dependendo esse aspecto, diretamente, do modo como as características da inovação são percebidas pela organização que adotará a tecnologia. Com isso em vista, as seguintes proposições são lançadas:

Proposição 01: Os esforços de marketing do fornecedor foram determinantes das características percebidas da inovação adotada na empresa do segmento de automação industrial.

Proposição 02: As redes sociais (social network) foram determinantes das características percebidas da inovação adotada na empresa do segmento de automação industrial.

Proposição 03a: As influências do ambiente foram determinantes das características percebidas da inovação adotada na empresa do segmento de automação industrial.

Proposição 03b: As influências do ambiente foram determinantes do processo de adoção de tecnologia na empresa do segmento de automação industrial.

Proposição 04: As características percebidas da inovação foram determinantes do processo de adoção de tecnologia na empresa do segmento de automação industrial.

Proposição 05: As características dos adotadores foram determinantes do processo de adoção de tecnologia na empresa do segmento de automação industrial.

\section{Metodologia}

A presente seção apresenta as estratégias de pesquisa e a técnica de coleta de dados utilizada, além de descrever a empresa e apresentar o caso em estudo. Por acordo com a empresa estudada, utilizaremos um nome fictício, portanto, a empresa é denominada nesse artigo de EMPRESA ALFA LTDA.

\subsection{Estratégia de pesquisa e técnica de coleta}

As investigações da pesquisa buscou responder à seguinte pergunta-problema: como uma empresa do segmento de automação industrial adota tecnologias? A resposta a essa pergunta, do ponto de vista metodológico, exigiu o uso do estudo de caso como método de 
pesquisa, uma vez que, a pergunta proposta traz em si a necessidade de entender como a empresa adota a tecnologia, e o entendimento do "como" e "por que" remete ao estudo de caso como método mais adequado (Cooper \& Schindler, 2011; Godoy, 1995; Gil, 1996; Campomar, 1991).

O estudo de caso é caracterizado "como um tipo de pesquisa cujo objeto é uma unidade que se analisa profundamente" (Godoy, 1995) e, como metodologia de pesquisa, combina entrevistas, individuais ou em grupo, com análises documentais, objetivando obter perspectivas múltiplas de uma única organização, situação, evento ou processo em um ponto no tempo ou por um período de tempo (Cooper \& Schindler, 2011). Na presente pesquisa foram consideradas as perspectivas de uma única organização em um ponto no tempo.

A condução de um estudo de caso encontra respaldo em algumas etapas com vistas a obter um bom resultado no uso do método, sendo elas: definição clara do problema a ser pesquisado; desenho da estrutura de coleta de dados e das principais perguntas; decisão de estudos de natureza global ou de natureza encaixada; elaboração de um protocolo com atividades a serem realizadas e procedimentos a serem utilizados; e definição dos instrumentos para a coleta de dados (Yin, 1990).

Definido o problema desta pesquisa, optou-se pelo estudo de caso simples como estrutura de coleta de dados, uma vez que o fenômeno estudado é passível de ser entendido com a análise de uma única organização, no caso, o objeto do estudo. Assim, realizou-se um estudo abrangendo os elementos do framework como um todo, e utilizou-se, para tanto, entrevista estruturada como instrumento de coleta de dados. A entrevista foi aplicada com o gerente de Pesquisa, Desenvolvimento e Engenharia da EMPRESA ALFA LTDA, o qual atua na empresa desde 1992.

O roteiro de entrevista estruturada foi construído com base nos framework de adoção de inovações em organizações propostos por Frambach e Schillewaert (2002). Para cada aspecto apontado pelos modelos, foi construída uma pergunta com vistas a conhecer a relevância do item para a empresa no tocante à adoção de tecnologia. A entrevista foi aplicada em 2014, e os áudios foram transcritos e as análises realizadas a partir das transcrições.

\subsection{Descrição da empresa estudada e apresentação do caso}

A empresa objeto do presente estudo é a EMPRESA ALFA LTDA, nome fictício. Empresa fundada em 1976 com o objetivo de explorar o segmento de automação industrial. Iniciativa de dois engenheiros recém-formados, a empresa veio ao longo dos anos consolidando a sua atuação no mercado a ponto de se tornar uma das maiores empresas do segmento, projetando sua atuação em grande parte do território brasileiro e, também, no exterior, mais especificamente em países da América Latina do Norte, Europa e Ásia.

A história da organização começa no ano acima citado, tendo a empresa, inicialmente, instalações fixadas em São Paulo, e posteriormente, mais especificamente no início da década de 1990, transferiu suas instalações fabris para a cidade de Santa Rita do Sapucaí, localizada ao sul do estado de Minas Gerais, visando explorar o potencial que a região apresentava no segmento de eletrônicos e a proximidade com alguns centros de conhecimento.

A EMPRESA ALFA LTDA, atualmente, trabalha em dois segmentos de mercado, sendo eles: Factory, segmento que trabalha com um portfólio de produtos voltados para sensores de proximidade para chão de fábrica, ou seja, automação de fábrica; e o PA (Process Automation), ou seja, automação de processos, segmento que atende plantas industriais de 
segmentos como açúcar, álcool, petróleo e gás. Dentro do segmento de PA, a EMPRESA ALFA LTDA vem buscando desenvolver produtos com vistas a atender a demanda das plantas industriais por sistemas de controle de quatro variáveis de processos: pressão; vazão; temperatura; e posicionadores.

\section{A EMPRESA ALFA LTDA do ponto de vista da Estrutura Organizacional}

A estrutura organizacional da EMPRESA ALFA LTDA passou por algumas adequações nos últimos anos. De início, a estrutura era tipicamente funcional, sendo composta por uma diretoria, materializada na figura dos dois sócios, e onze gerencias. Tendo em vista os direcionamentos voltados para a inovação e tecnologia, a empresa percebeu a importância de tornar a estrutura mais compatível para essas diretivas, criando, portanto, o comitê técnico e da qualidade, com vistas a deliberar sobre assuntos técnicos, promovendo assim a diferenciação e desenvolvimento de novos produtos de maneira integrada dentro da organização. Esse comitê é composto pelo gerente de pesquisa, desenvolvimento e inovação; a engenharia industrial; o departamento de marketing; o departamento comercial e a diretoria, conforme mencionado pelo entrevistado.

O objetivo maior desse comitê é selecionar e definir Novos Projetos Inovadores que comporão o portfólio de projetos da organização com vistas a ampliar o portfólio de produtos. Dentre as atividades realizadas pela gerência de pesquisa, desenvolvimento e inovação e apresentadas ao comitê encontra-se a elaboração de roadmaps estratégicos para o acompanhamento e promoção do desenvolvimento tecnológico da organização.

Com base nas decisões do comitê técnico e da qualidade, alguns outros subcomitês são criados com vistas a planejar, executar e acompanhar os projetos definidos pelo comitê. Esses subcomitês são denominados Subcomitês de Formalização e Validação de Novos Projetos, e são compostos por equipes multifuncionais, integrando membros das mais diversas áreas da organização, fazendo com que os projetos sejam, dessa forma, amparados pelas várias áreas da organização dentro de uma estrutura matricial.

\section{Descrição da Tecnologia Adotada - O caso em estudo}

A EMPRESA ALFA LTDA, seguindo sua estratégia de desenvolvimento de produtos para atacar potenciais mercados, viu-se diante da decisão de adotar uma tecnologia necessária para o desenvolvimento de mais quatro linhas de produtos a serem agregadas ao seu portfólio. Esses produtos são direcionados ao segmento de automação de processos industriais, sendo, portanto, referentes ao controle de quatro variáveis de processos, sendo elas: vazão, pressão, temperatura e posicionador, utilizando a tecnologia HART.

Para tanto, a empresa se viu diante da necessidade de adotar o protocolo HART para desenvolvimento dos produtos mencionados, sendo, portanto, a tecnologia foco desse estudo e que colocou a empresa diante da decisão de adoção de tecnologia. O protocolo HART (Highway Addressable Remote Transducer) é um protocolo digital de comunicação bidirecional, introduzido em 1989, sendo o primeiro dos protocolos digitais de comunicação a não apresentar interferências nos sinais analógicos de controle.

Como principais características dessa tecnologia, são citados, segundo Cassiolato (2014):

(1) Comprovado na prática, projeto simples, fácil operação e manutenção; 
(2) Compatível com a instrumentação analógica;

(3) Sinal analógico e comunicação digital;

(4) Opção de comunicação ponto-a-ponto ou multidrop;

(5) Flexível acesso de dados usando-se até dois mestres;

(6) Suporta equipamentos multivariáveis;

(7) 500min de tempo de resposta (com até duas transações);

(8) Totalmente aberto com vários fornecedores.

O protocolo HART, segundo Cassiolato (2014), “opera segundo o padrão MestreEscravo, onde o escravo somente transmitirá uma mensagem se houver uma requisição do mestre". Assim, a comunicação em rede tem início com o comando do mestre, a partir do qual, o escravo emitirá a resposta, e todo o tempo de transmissão da informação entre mestre e escravo é controlado, existindo inclusive, um controle de tempo entre dois mestres quando for o caso.

Quando se menciona mestre, refere-se ao controlador em redes de comunicação, a exemplo do PLC (Power Line Communication) ou SDCD (Sistema Digital de Controle Distribuído). São equipamentos de automação industrial tendo como objetivo maior o controle de processos visando melhorar produtividade e reduzir custos em plantas industriais por meio da melhoria da qualidade dos produtos e precisão das operações, tudo isso com uma segurança operacional e monitoramento do processo de produção via comunicação em rede.

A figura abaixo, retirada de Cassiolato (2014), permite visualizar a dinâmica de informações em um frame de requisição HART:

Figura 02 - Frame HART

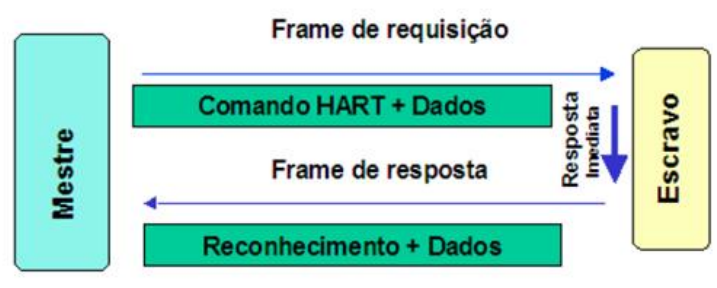

FONTE: Cassiolato (2014)

\section{Análise E Discussão Dos Resultados}

A adoção de tecnologia e, portanto, a análise da decisão de adoção de tecnologias, conforme apontou Rogers (2003), depende do que se entende pela unidade de adoção a ser analisada, podendo ser esta individual ou organizacional. Quando a análise da adoção de tecnologia parte do nível individual tem-se a taxa de adoção como sendo influenciada pelas variáveis apontadas pelo autor, ou seja, os atributos da inovação. Quando a análise da adoção tem como unidade de análise uma organização, ou um grupo de pessoas, por exemplo, pode acontecer de não se observar todos os atributos de inovação como sendo fatores determinantes para a adoção.

Dessa perspectiva, é preciso tornar claro a unidade de análise utilizada nessa pesquisa: a EMPRESA ALFA LTDA. A adoção da tecnologia aqui analisada aconteceu em nível 
organizacional. A tecnologia adotada pela organização foi descrita na seção anterior, sendo, portanto, fundamental o entendimento da tecnologia, bem como de suas características, visto que, os atributos da inovação citados por Rogers (2003) e assumidos por Frambach e Schillewaert (2002) como características percebidas da inovação podem ser percebidos de maneira diferente a depender da tecnologia em análise.

Analisando as proposições levantadas na pesquisa, temos que, quando considerado o proposição 01 (Os esforços de marketing do fornecedor foram determinantes das características percebidas da inovação na empresa do segmento de automação industrial), foi enfatizado na entrevista que os esforços de marketing do fornecedor não determinaram as características percebidas da tecnologia adotada. Segundo o entrevistado, o tipo de tecnologia de que estamos tratando já é bem conhecida no mercado, existindo, inclusive, outras tecnologias semelhantes, mas que essa, por alguns atributos ou características percebidas, é julgada mais compatível com o tipo de intenção que a empresa tem para essa tecnologia, o que independe dos esforços do fornecedor, o que caminha na direção contrária da proposição levantada.

Frambach e Schillewaert (2002), assim como Nemoto, Vasconcellos e Nelson (2010) apontam o fator "influencia do fornecedor" como aspecto relacionado às características percebidas da inovação. Frambach e Schillewaert (2002) apontam o alvo, a comunicação e a redução de riscos fornecidos por parte dos fornecedores como determinantes das características percebidas de uma tecnologia, e Nemoto, Vasconcellos e Nelson (2010) apontam, além dos fatores apresentados, a reputação e a dependência do fornecedor da tecnologia como aspectos também analisados e relacionados diretamente à decisão para adotar uma inovação.

Assim como afirma Rogers (2003), a adoção de tecnologias quando se considera a organização como unidade de análise remete, não necessariamente, a serem utilizados ou considerados todos os atributos ou aspectos apontados nos modelos aqui apresentados. A observação dos fatores apresentados nos modelos no momento da adoção da tecnologia depende também do tipo de tecnologia que se está adotando. No caso em estudo, o tipo de tecnologia, segundo aponta o entrevistado, é normalizado, o que significa que a qualidade não tem diferenças significativas entre um fornecedor e outro, o que fez com que a escolha do fornecedor fosse feita com base na análise de custo-benefício.

Quando considerado as redes sociais (social network), Frambach e Schillewaert (2002) consideram a interconectividade ou participação em redes como um fator determinante na formação das características percebidas da inovação. Nemoto, Vasconcellos e Nelson (2010) engloba esse fator dentro de outro conjunto de aspectos, denominado por eles como "características organizacionais", o que inclui os seguintes aspectos: redes sociais internas; redes sociais externas; e desejo da cúpula de gestores para inovar.

Esse aspecto permitiu levantar a proposição 02 (As redes sociais foram determinantes das características percebidas da inovação adotada na empresa de automação industrial). Foi enfatizada na entrevista a experiência adquirida pela organização ao longo dos seus 38 anos de atuação no segmento de automação industrial. Não se evidenciou a participação em redes, tampouco a influência no processo de decisão de adoção da tecnologia, porém, deixou transparecer, ao longo da sua fala, características de conexão em redes informais com outras organizações: fornecedores e concorrentes. Apresentou um conhecimento bastante forte no sentido de identificar quais empresas dominam cada tecnologia, e com isso, deixou transparecer entendimento adquirido ao longo dos anos sobre tecnologias, resultado de 
participação em feiras internacionais, feiras do segmento, e eventos do tipo, o que se caracteriza assim, como um conhecimento adquirido via interconectividade, participação em redes (Frambach e Schillewaert, 2002) e redes sociais informais (Nemoto, Vasconcellos e Nelson, 2010).

Com relação à influência ambiental (Frambach \& Schillewaert, 2002) ou ambiente externo (Nemoto, Vasconcellos \& Nelson, 2010), duas proposições foram levantadas: Proposição 03a (As influências do ambiente foram determinantes das características percebidas da inovação adotada) e Proposição 03b (As influências do ambiente foram determinantes do processo de adoção da tecnologia na empresa do segmento de automação industrial). $\mathrm{Na}$ entrevista, foi bastante enfatizado a existência de pressões competitivas guiando a atuação da empresa no mercado. Segundo dados da entrevista,

“[...] Hoje o mercado quando fala nessas quatro variáveis de processo: pressão, vazão, temperatura e posicionamento, o mercado, ou ele vai falar em um equipamento usando HART ou PROFIBUS-PA, então existe sim [pressão do ambiente externo], a gente está totalmente sendo guiado aí por uma imposição de mercado, o mercado compra isso."

Aqui é importante evidenciar que a pressão do ambiente externo vem mais na direção cliente-empresa do que na direção concorrência-empresa. Logo, a adoção da tecnologia, conforme foi relatado na entrevista, teve um impulso bastante forte do ponto de vista das exigências dos clientes. Quando questionado sobre o impacto dos concorrentes na decisão de adoção, o entrevistado apontou não ter havido influências dos concorrentes, visto que, a aquisição da tecnologia foi resultante de um potencial mercado identificado, e cujos clientes potenciais apresentam suas preferências por tecnologia HART ou PROFIBUS-PA, lembrando que a tecnologia HART apresenta menos interferências na lida com sinais analógicos de controle.

Teoricamente, o modelo apresentado por Frambach e Schillewaert (2002) trata como influências ambientais as variáveis "externalidades de rede" e "pressões competitivas". Já Nemoto, Vasconcellos e Nelson (2002) incluem, além dessas duas citadas, as "características da cadeia de produção"; a "incerteza com relação ao mercado"; e a "regulação governamental". A empresa, no momento da adoção do protocolo HART, apresentou tranquilidade no quesito características da cadeia de produção, uma vez que, conforme relatado, a equipe técnica responsável pela assimilação e absorção dessa tecnologia é bastante qualificada, sendo, portanto, de fácil adequação da tecnologia à linha de produção, podendo aqui, considerarmos a influência da cadeia de produção como positiva, ou seja, pesou mais positivamente do que negativamente no momento da adoção da tecnologia.

Com relação aos atributos da inovação (Rogers, 2003; Nemoto, Vasconcellos \& Nelson, 2010) ou características percebidas da inovação (Frambach e Schillewaert, 2002), foi levantada a proposição 04 (As características percebidas da inovação foram determinantes para o processo de adoção da tecnologia na empresa do segmento de automação industrial). Os achados da entrevista indicaram evidências de forte relação entre as características percebidas da inovação e a decisão de adotar a tecnologia. Conceitualmente, Frambach e Schillewaert (2002), Rogers (2003) e Nemoto, Vasconcellos e Nelson (2010) apresentam coerência quando considerado os atributos, todos eles descrevem como atributos: vantagem relativa da tecnologia, compatibilidade, complexidade, possibilidade de teste da tecnologia, 
visibilidade e incerteza. Há uma pequena diferença apresentada no modelo de Nemoto, Vasconcellos e Nelson (2010) com relação às vantagens relativas, uma vez que estes autores consideram dois tipos de vantagens relativas: qualitativa e econômica.

Quando questionado sobre as vantagens comparativas da tecnologia, o entrevistado afirmou que não as levam muito em consideração, uma vez que, segundo ele, não se pode considerar em termos comparativos, por exemplo, a tecnologia HART e a tecnologia PROFIBUS-PA, pois, cada uma é indicada para certo tipo de controle de variáveis dentro do processo de automação industrial, seja automação de fábrica ou automação de processos. Apesar disso, o entrevistado enfatizou que as tecnologias HART e PROFIBUS-PA são mais confiáveis, cada uma em sua funcionalidade, deixando transparecer certa vantagem comparativa em relação a outras tecnologias.

Como mencionado na entrevista:

"Existe hoje um domínio de quem usa [tecnologias HART ou PROFIBUSPA], apesar de poder usar outras tecnologias, mas as duas nesse segmento é que são adotadas, por quê? Por que são extremamente confiáveis. Esse protocolo, esse procedimento de... ele não foi adotado a toa, ele foi adotado pela confiabilidade dele, num processo em que isso é extremamente importante, a questão da confiabilidade.”

"Então, o protocolo HART e o protocolo PROFIBUS-PA, aí a gente faz uma ressalva para o HART, com mais propriedade, eles têm muita afinidade para tratar variáveis analógicas de forma extremamente confiável, então por isso ele é mais adequado para essa situação de automação de processos, de tratativa dessas quatro variáveis, entendeu? É isso, ele é mais adequado, é mais rápido [...]. Ele é mais confiável do ponto de vista de tratar essas variáveis."

Fica evidente que a confiabilidade dessas tecnologias é um importante atributo que implica diretamente na decisão de adoção da tecnologia nas organizações. Com relação à compatibilidade, o entrevistado não demonstrou preocupação, o que deixou transparecer que a questão da compatibilidade com a organização é um fator que não pesa negativamente na decisão de adoção, uma vez que a tecnologia é compatível com a estrutura e os valores da organização. Já a complexidade da tecnologia foi um fator citado pelo entrevistado com a preocupação unicamente voltada para o time to market, ou seja, apresentou-se forte preocupação com a complexidade da tecnologia, não no sentido da organização não ser capaz de absorvê-la, mas sim, no sentido de tempo despendido para a absorção.

A possibilidade de teste, outro atributo da inovação defendido pelos autores na literatura, não foi citado na entrevista. $O$ que foi mencionado nesse sentido refere-se à designação de uma equipe da empresa em uma incursão na empresa fornecedora da tecnologia, a fim de aprender manusear a tecnologia, para, a partir daí, absorver e utilizá-la. Trata-se mais de um treinamento no uso da tecnologia, não havendo uma fase beta, por exemplo, conforme aponta Rogers (2003) e Frambach e Schillewaert (2010).

Com relação aos últimos dois atributos mencionados na literatura, visibilidade e incerteza, pode-se perceber que a tecnologia apresenta uma visibilidade bastante forte no mercado, principalmente entre os clientes, ou seja, indústrias que utilizam a tecnologia HART na automação de processos em suas plantas para controle das quatro variáveis de processos já 
citadas anteriormente. Além do mais, com relação à incerteza, a tecnologia, de certa forma, apresenta um grau de incerteza baixo, uma vez que já é uma tecnologia que já foi inserida no mercado e tem apresentado, portanto, desempenho satisfatório.

Outro aspecto apontado na literatura (Frambach \& Schillewaert, 2002; Nemoto, Vasconcellos \& Nelson, 2010; Rogers, 2003; Thong \& Yap, 1995) são as características dos adotadores, sendo abordados nesse quesito, os indicadores: tamanho, estrutura, postura estratégia ou organização para inovação (Frambach \& Schillewaert, 2002), redes sociais internas, redes sociais externas, e desejo da alta cúpula de gestão para inovar (Nemoto, Vasconcellos e Nelson, 2010). Foi levantada a proposição 05 (As características dos adotadores foram determinantes do processo de adoção da tecnologia na empresa do segmento de automação industrial). Identificou-se na entrevista que a organização apresenta uma postura inovativa, sendo a inovação um dos princípios que norteia a organização, assim como mencionado na descrição da organização na seção anterior. Além do mais, apresenta uma equipe capacitada para desenvolver produtos nesses segmentos e capaz de assimilar as tecnologias disponíveis no mercado. Assim, percebe-se que as características apresentadas pela organização como adotador da tecnologia foram aspectos que pesaram positivamente no processo de decisão de adoção da tecnologia.

Como fechamento da análise, em resumo, temos que a adoção da tecnologia foi uma decisão conjunta de um comitê com tal função dentro da organização, não havendo influencia direta do CEO. Além do mais, tendo em vista as características apontadas pela tecnologia, o fator esforços do fornecedor não foi relevante, ou, conforme citado na entrevista, não existiu de maneira direta. Houve uma participação da empresa em feiras e eventos, o que caracteriza a conectividade da empresa e participação em redes, mesmo que informais, sendo que, pelo que pôde ser percebido, essa interconectividade influenciou diretamente o conhecimento da organização com relação à tecnologia, evidenciando os atributos por ela apresentado e deixando transparecer que a relação dessas redes sociais com a decisão de adoção da tecnologia é mesmo indireta, conforme indicado no modelo de Frambach e Schillewaert (2010).

As pressões competitivas foram significativas, principalmente reflexo das exigências dos clientes, os quais preferem mecanismos de controle das variáveis de processos mediante o uso de tecnologia HART, não havendo pressões julgadas relevantes pelos entrevistados no que se refere à concorrência. E por fim, as características da organização como adotador da tecnologia foram consideradas e julgadas mais como um impulsionador para a adoção do que uma barreira, tendo em vista a postura estratégica da organização voltada para inovação, o tamanho da organização e a estrutura organizacional e de equipe capaz de absorver e inserir a tecnologia em seus processos.

\section{Conclusão e Considerações Finais}

O objetivo do presente artigo foi analisar a adoção de tecnologia em uma empresa do segmento de automação industrial, tendo como objetivo operacional identificar os fatores considerados na tomada de decisão para adoção da mesma. Para tanto, a análise da adoção foi realizada tomando como base o modelo de adoção de tecnologia de Frambach e Schillewaert (2002). Utilizando o estudo de caso como técnica de pesquisa, foi possível alcançar os objetivos propostos. As proposições que direcionaram a pesquisa estão apresentadas no quadro 01 . 


\begin{tabular}{|l|l|}
\hline Proposição & Descrição \\
\hline Proposição 01 & $\begin{array}{l}\text { Os esforços de marketing do fornecedor foram determinantes das características } \\
\text { percebidas da inovação adotada na empresa do segmento de automação industrial }\end{array}$ \\
\hline Proposição 02 & $\begin{array}{l}\text { As redes sociais (Social Network) determinaram as características percebidas da inovação } \\
\text { adotada na empresa do segmento de automação industrial }\end{array}$ \\
\hline Proposição 03a & $\begin{array}{l}\text { As influências do ambiente determinaram as características percebidas da inovação } \\
\text { adotada na empresa do segmento de automação industrial }\end{array}$ \\
\hline Proposição 03b & $\begin{array}{l}\text { As influências do ambiente determinam o processo de adoção de tecnologia na empresa } \\
\text { do segmento de automação industrial }\end{array}$ \\
\hline Proposição 04 & $\begin{array}{l}\text { As características percebidas da inovação determinaram o processo de adoção da } \\
\text { tecnologia na empresa do segmento de automação industrial }\end{array}$ \\
\hline Proposição 05 & $\begin{array}{l}\text { As características dos adotadores determinaram o processo de adoção da tecnologia na } \\
\text { empresa do segmento de automação industrial }\end{array}$ \\
\hline
\end{tabular}

\section{Quadro 01 - Proposições da pesquisa}

FONTE: Elaborado pelos autores.

A tecnologia adotada pela empresa, e caso do estudo, foi o protocolo HART, recentemente adotado pela empresa para desenvolver produtos voltados para o controle das variáveis de processos: vazão, temperatura, pressão e posicionador. O protocolo HART é um protocolo digital de comunicação bidirecional, sendo o primeiro dos protocolos digitais de comunicação a não apresentar interferências nos sinais analógicos de controle. Esse protocolo permite o desenvolvimento de produtos com vistas ao controle de variáveis de processos mediante a comunicação em rede por meio de um mecanismo de mestre-escravo, no qual o mestre emite a informação e o escravo responde, sendo condição prévia para a obtenção dessa resposta, a solicitação feita pelo mestre.

No setor de automação industrial, o qual, de maneira geral, abrange os segmentos de factory, cujos produtos são voltados para a automação de fábrica; e PA (Process Automation), cujos produtos são voltados para a automação de processos, são utilizados dois tipos de protocolos, sendo eles o HART e o PROFIBUS-PA. A tecnologia HART tem se mostrado a mais confiável, segundo indicado na entrevista, no quesito automação de processos via redes de comunicação, uma vez que é mais adequado para tratar as variáveis mencionadas anteriormente.

Pode-se mencionar - fundamentado na entrevista com o gerente de Pesquisa, Desenvolvimento e Inovação da EMPRESA ALFA LTDA - que os fatores considerados no processo de adoção da tecnologia foram: influência do ambiente; características da organização; e características percebidas da inovação. Apesar de não ser citado, verificou-se também que a organização participa de redes informais e se mantém interconectada com fornecedores, clientes e concorrentes via participação em eventos do tipo feiras internacionais e nacionais de exposição de inovações, dentre outros.

Diante disso, percebeu-se que os resultados estão alinhados com as proposições 02, 03a, 03b, 04 e 05. Porém, os resultados deram indícios de que os esforços de marketing dos fornecedores não foram determinantes para a percepção das características da tecnologia adotada, o que rechaça a primeira hipótese. Apesar do estudo não permitir generalizações, os resultados encontrados levantam hipóteses para estudos futuros, no sentido de verificar se os elementos do modelo são identificados na adoção de tecnologias em diferentes setores. No segmento de automação industrial, há indícios de que, para a adoção da tecnologia estudada, 
os esforços de marketing do fornecedor não interferem nas decisões de adoção da tecnologia pela organização.

Assim, retomando o modelo utilizado para a pesquisa, proposto por Frambach e Schillewaert (2002), pode-se visualizar com maior nitidez os fatores considerados na tomada de decisão, conforme demostra a figura 3.

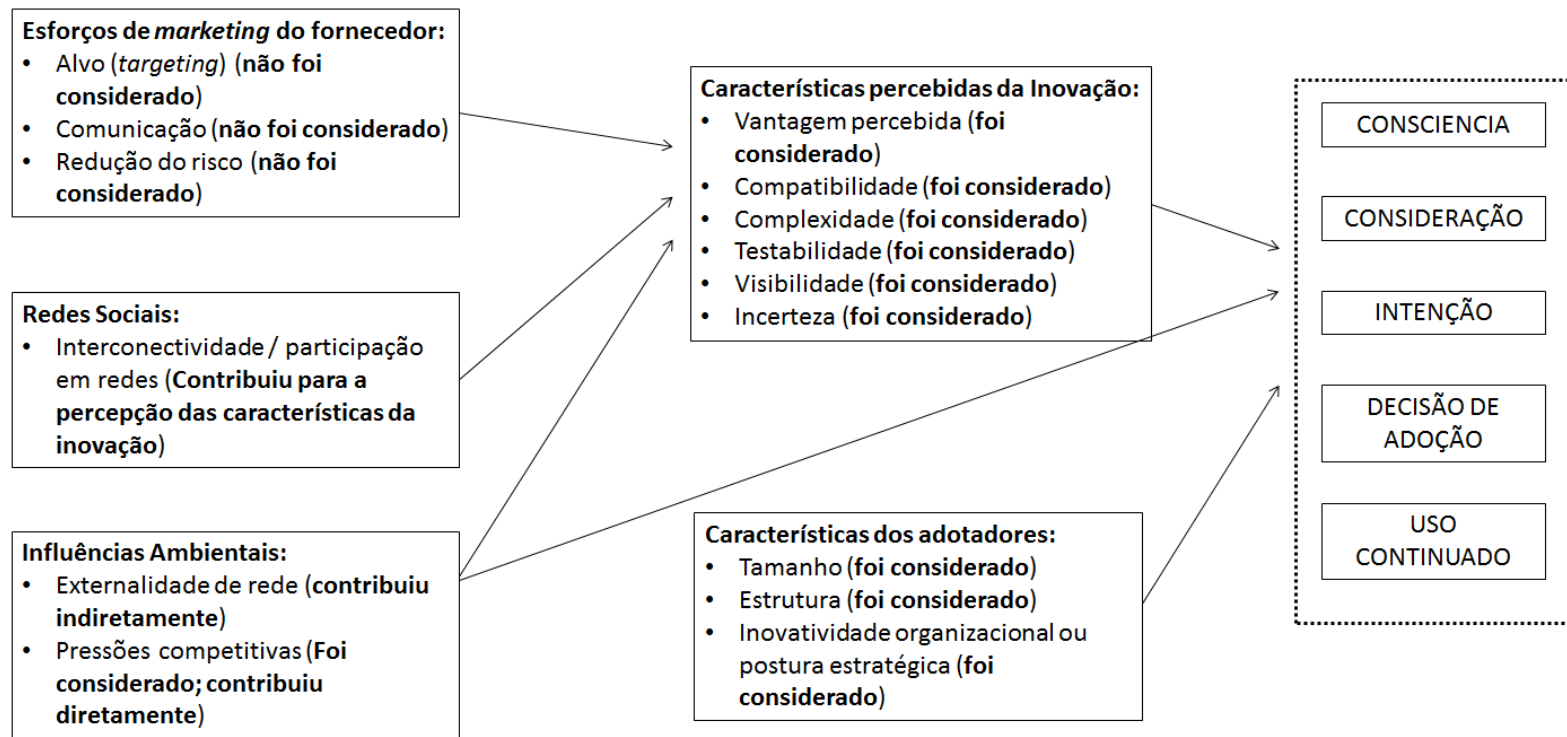

Figura 03 - Framework conceitual de Frambach e Schillewaert (2002) com indicações de fatores que foram considerados pela empresa estudada

FONTE: Elaborado pelo autor com base no Framework apresentado por Frambach e Schillewaert (2002).

O presente artigo apresenta algumas limitações que precisam ser apontadas. A primeira delas é que, tendo em vista a característica do método utilizado, não é possível proferir generalizações dos resultados até que se faça um estudo quantitativo passível de generalizações. Além do mais, os resultados precisam ser analisados com cuidados, uma vez que, não houve entrevistas em profundidade com os stakeholders indicados no modelo, sejam eles fornecedores ou clientes, sendo, portanto, uma análise do ponto de vista da empresa adotante da tecnologia. Por se tratar de um estudo inicial sobre o tema, outros estudos são necessários para esclarecer evidências identificadas nessa pesquisa, e ampliar o escopo das análises utilizadas.

Diante disso, os resultados encontrados podem ser considerados como hipóteses para estudos futuros, o que sugere a utilização de uma metodologia quantitativa com estudos que abranjam uma amostra significativa de empresas do segmento de automação industrial. Estudos desse tipo permitem generalizações e facilita a visualização de níveis de importância entre os fatores considerados para a adoção de tecnologia. Além disso, é bem vindo ainda, estudos que envolvam uma análise do ponto de vista dos diferentes stakeholders do processo de adoção pela empresa.

Por fim, como contribuições acadêmicas do estudo, foi possível visualizar como a empresa estudada - atuante do segmento de automação industrial - adota tecnologia e quais os fatores foram considerados para que a adoção acontecesse, além de permitir a geração de hipóteses e sugestões para estudos futuros nessa área. Como contribuições gerenciais do estudo, o artigo coloca os gestores frente a um caso que pode servir como benchmarking para 
empresas do mesmo segmento, uma vez que a adoção da tecnologia foi bem sucedida, e pode, além do mais, permitir que os gestores da função de $P \& D$ atentem-se para os fatores que impulsionaram a adoção da tecnologia na empresa estudada.

\section{Referências}

Bowonder, B., Dambal, A., Kumar, S., \& Shirodkar, A. (2010). Innovation strategies for creating competitive advantage. Research-technology management, 53(3), 19-32.

Campomar, M. C. (1991). Do uso de "estudo de caso" em pesquisas para dissertações e teses em administração. Revista de Administração, São Paulo, 26(3).

Cassiolato, C. (2014). Hart sobre o Profibus. Artigo Técnico. SMAR Equipamentos Industriais. Recuperado em 15/11/2014, de: http://www.smar.com/brasil/artigo-tecnico/hartsobre-o-profibus

Chesbrough, H. Open Innovation: The imperative for creating and profiting from technology. Harvard Business School Press.

Cooper, D. R., \& Schindler, P. S. (2011). Métodos de Pesquisa em Administração. 10a ed., Porto Alegre: Bookman.

Frambach, R. T., \& Schillewaert, N. (2002). Organizational innovation adoption: A multilevel framework of determinants and opportunities for future research. Journal of business research, 55(2), 163-176.

Gil, A. C. (1996). Como elaborar projetos de pesquisa. São Paulo: Atlas.

Godoy, A. S. (1995). Pesquisa qualitativa: tipos fundamentais. Revista de Administração de empresas, 35(3), 20-29.

Kumpe, T., \& Bolwijn, P. T. (1994). Toward the innovative firm-challenge for R\&D management. Research-Technology Management, 37(1), 38-44.

Lunardi, G. L., Dolci, P. C., \& Maçada, A. C. G. (2010). Adoção de tecnologia de informação e seu impacto no desempenho organizacional: um estudo realizado com micro e pequenas empresas. Revista de Administração, 45(1), 5-17.

Naranjo-Gil, D. (2009). The influence of environmental and organizational factors on innovation adoptions: Consequences for performance in public sector organizations. Technovation, 29(12), 810-818.

Neely, A., \& Hii, J. (1998). Innovation and business performance: a literature review. The Judge Institute of Management Studies, University of Cambridge, 0-65. 
Nemoto, M. C. M. O., Vasconcellos, E. P. G. D., \& Nelson, R. (2010). The adoption of new technology: conceptual model and application. Journal of technology management \& innovation, 5(4), 95-107.

Rogers, E. M. (2003). Diffusion of Innovations. 5a ed., New York: Free Press.

Thong, J. Y., \& Yap, C. S. (1995). CEO characteristics, organizational characteristics and information technology adoption in small businesses. Omega, 23(4), 429-442.

Yin, R. K. (1994). Case Study Research: design and methods. EUA: Sage Publications. 